Role of Endoscopic Retrograde CholangioPancreatography (ERCP) and Intraductal Secretin Test (IDST) in the Diagnosis of Chronic Pancreatitis (CP)

Vitalis C. Osuji, Gail McNulty, RN, BSN, CCRC, Evan Fogel, MD, MSc, FRCP(C)

Indiana University School of Medicine and Indiana University Hospital

Division of Digestive and Liver Diseases

\title{
Background:
}

$\mathrm{CP}$ may be difficult to diagnose in the early stages when imaging may be normal. An IDST performed at ERCP may further evaluate for $\mathrm{CP}$, with determination of pure pancreatic juice (PPJ) volume and bicarbonate concentration (BC). The optimal collection time for IDST is unknown. We report our experience with the IDST in 447 patients with suspected CP.

\section{Experimental Design:}

IDSTs performed from 2006-2018 were reviewed, with fluid collected at 5-min intervals for 20-60 minutes. Parameters evaluated were PPJ volume, Secretory Flow Rate (SFR), time of peak SFR, maximum BC and time to maximum BC.

\section{Results:}

Maximum BC was reached by 10-min in 59 patients (13.2\%); 15-min: 207 patients (46.3\%); 20 min: 340 patients (76.1\%); 25-min: 384 patients (85.9\%); 30-min: 421 patients (94.1\%). Peak SFR was reached by 10 -min in 92 patients $(20.6 \%)$; 15 min: 177 patients (39.6\%); 20-min: 240 patients (53.7\%); 25-min: 284 patients (63.5\%); 30-min: 323 patients (72.3\%). Final diagnosis (normal vs. CP) for both SFR and BC was determined by 20-min (i.e. in CP pts, either the SFR or BC was low (SFR $<3 \mathrm{ml} / \mathrm{min}, \mathrm{BC}<105 \mathrm{mEq} / \mathrm{L}$ ) and remained low throughout collection, or normal $(>3 \mathrm{ml} / \mathrm{min}$ and $>105 \mathrm{mEq} / \mathrm{L})$ within the first $20-\mathrm{min}$. Further collection did not change the diagnosis.

\section{Conclusion:}

At IDST, a 20-minute collection period is necessary to categorize patients into normal or suspected CP groups. A study in control patients (no suspicion of CP) to validate these data is currently underway. 